\title{
Cancer targeting with biomolecules: A comparative study of photodynamic therapy efficacy using antibody or lectin conjugated phthalocyanine-PEG gold nanoparticles
}

Girgis Obaid, Isabelle Chambrier, Michael J. Cook and David A. Russell*

School of Chemistry, University of East Anglia, Norwich Research Park, Norwich, Norfolk, NR4 $7 T J, U K$

*E-mail: d.russell@uea.ac.uk

\begin{abstract}
The functionalisation of therapeutic nanoparticle constructs with cancer-specific biomolecules can enable selective tumour accumulation and targeted treatment. Water soluble gold nanoparticles (ca. $4 \mathrm{~nm}$ ) stabilised by a mixed monolayer of a hydrophobic zinc phthalocyanine photosensitiser (C11Pc) and hydrophilic polyethylene glycol (PEG) have been prepared. The C11Pc-PEG gold nanoparticle constructs were further functionalised with jacalin, a lectin specific for the cancer-associated Thomsen-Friedenreich $(T)$ carbohydrate antigen, or with monoclonal antibodies specific for the human epidermal growth factor receptor-2 (HER-2). The two biofunctionalised nanoparticle conjugates produced similar levels of singlet oxygen upon irradiation at $633 \mathrm{~nm}$. Importantly, both nanoparticle conjugates demonstrated extensive, yet comparable, phototoxicity in HT-29 colorectal adenocarcinoma cells (80-90\%) and in SK-BR-3 breast adenocarcinoma cells (>99\%). Non-conjugated C11Pc-PEG gold nanoparticles were only minimally phototoxic. Lysosomal colocalisation studies performed with the HT-29 colon cancer cells and the SK-BR-3 breast cancer cells revealed that both nanoparticle conjugates were partially localised within acidic organelles, which is typical of receptor-mediated endocytosis. The similarity of the targeted PDT efficacy of the two biofunctionalised C11Pc-PEG gold nanoparticles is discussed with respect to targeting ligand binding affinity and cell surface antigen density as key determinants of targeting efficiency. This study highlights how targeting small cell-surface molecules, such as the $T$ antigen, can mediate a selective photodynamic treatment response
\end{abstract}


which is similar to that achieved when targeting overexpressed protein receptors, such as HER2. The high prevalence of the $T$ antigen present on the cellular surface of primary tumours emphasises the broad potential applications for lectin-targeted therapies.

\section{Introduction}

Photodynamic therapy (PDT) is based on the photochemical reaction between light and photosensitisers to generate therapeutic doses of cytotoxic singlet oxygen to efficiently treat cancers. ${ }^{1}$ Recently, a broad range of studies have reported the improved therapeutic efficacy and enhanced pharmacokinetic behaviour of some photosensitising agents when coupled to nanoparticles. ${ }^{2}$ Furthermore, nanoparticle systems can provide a robust platform for the conjugation of targeting agents in order to maximise the tumour selectivity of the photosensitiser-nanoparticle conjugate, while minimising any possible damage to healthy tissue. $^{2}$ Targeted nanoparticle platforms exhibit an additional advantage over conventional bioconjugates in that they display multivalent effects and enhanced tumour avidity through the existence of multiple targeting ligands at the surface of an individual nanoparticle entity. ${ }^{3}$

Active targeting of cancerous tissue relies on the identification of exogenous ligands with inherent or acquired selectivities and high binding affinities towards tumour-associated molecular targets. Overexpressed or newly expressed cell surface receptors that are not usually expressed in healthy cells are typical targets for selectively delivering cancer therapeutics to tumours. One of the most common methods of actively targeting tumour tissue is through the use of antibodies, antibody fragments or antibody mimetics, with an intrinsic therapeutic antitumour potential. ${ }^{4}$ Antibodies are particularly attractive for targeted cancer treatment due to their high binding affinities with equilibrium dissociation constants $\left(K_{d}\right)$ typically in the nanomolar range and also due to the broad range of pontential antigens. Antibody conjugates, so-called immunoconjugates, have seen wide-spread use for in vitro, in vivo and clinical cancer treatment. ${ }^{4}$ Within PDT, a number of studies have reported the direct conjugation of a photosensitiser with a cancer-targeting antibody to generate photoimmunoconjugates for selective PDT treatment. ${ }^{5}$ Levy et al. were the first to demonstrate the efficacy of using photoimmunoconjugates for 
targeted PDT. ${ }^{6}$ This approach has since been adapted for a variety of antibodies, photosensitisers and bioconjugation techniques. ${ }^{5}$ Recently, tumour-activatable photoimmunoconjugates composed of an anti-epidermal growth factor receptor (EGFR) antibody and a self-quenching photosensitiser benzoporphyrin derivative have been used to target in vivo OVCAR-5 human ovarian carcinomas overexpressing EGFR. ${ }^{7}$ Multimodal treatment using this photoimmunoconjugate demonstrated a potent synergistic therapeutic effect through the downregulation of EGFR receptor signalling in addition to selective photodynamic destruction of tumour tissue.

Human epidermal growth factor receptor-2 (HER-2) is of the EGFR tyrosine kinase family of transmembrane receptors which modulates a number of processes including apoptosis, migration, proliferation, growth, adhesion and proliferation. ${ }^{8}$ The HER-2 receptor is overexpressed in $10-34 \%$ of human breast cancers, and overexpression is correlated with poor disease prognosis. ${ }^{9}$ HER-2 overexpression directly increases cancer cell proliferation and migration, and also results in resistance to therapy and apoptotic induction. ${ }^{8}$ The HER-2 receptor is targeted in the clinic using the therapeutic monoclonal antibody trastuzumab (Herceptin), in particular for the treatment of HER-2 positive breast cancers. ${ }^{10}$ We have previously targeted human breast cancer cells that over-express the HER-2 receptor using zinc phthalocyaninepolyethylene glycol (C11Pc-PEG) stabilised gold nanoparticles conjugated to monoclonal antiHER-2 antibodies. ${ }^{11}$ Following irradiation, the antibody functionalised nanoparticles selectively reduced the viability of HER-2 overexpressing cells. MDA-MB-231 breast cancer cells not expressing the HER-2 receptor and subnormal, non-transformed MCF-10A breast epithelial cells were largely unaffected by the HER-2 targeted PDT treatment. ${ }^{11}$

An alternative cell surface target is the folate receptor. This receptor is overexpressed in more than $90 \%$ of human ovarian carcinoma cells and has therefore been extensively targeted with folate-chemotherapeutic conjugates to selectively deliver anti-cancer agents to tumour cells. ${ }^{12}$ One of the earliest reported studies showed the effective folate targeting of KB human nasopharyngeal cancer cells using a folate-conjugated liposomal preparation of chloroaluminium phthalocyanine..$^{13}$ More recently, folate modified porphysome structures have been described, that upon binding to tumour cell folate receptors, destabilise and become activated 
thus enabling their photosensitising potential. ${ }^{14}$ Likewise, transferrin bioconjugates have been widely used for monitoring disease progression and for the targeted destruction of cancer cells overexpressing the transferrin receptor. ${ }^{15}$ The first example of transferrin targeted PDT was reported by Hamblin and Newman who demonstrated that a transferrin-haematoporphyrin conjugate exhibited a superior PDT efficacy in HT-29 colon cancer and NIH:3T3 cells, as compared to an albumin-haematoporphyrin conjugate. ${ }^{16} \mathrm{~A}$ number of oligopeptides with specific affinities towards cancer-associated targets have been identified as powerful cancer-targeting biomolecules. These include peptides containing the arginine-glycine-aspartate (RGD) sequence which target $\alpha_{v} \beta_{3}$ and $\alpha_{v} \beta_{5}$ integrins that are overexpressed by a number of cancer cells and activated angiogenic vascular endothelial cells. ${ }^{17}$ The first evidence of the targeted PDT efficacy using RGD conjugates described the enhanced phototoxicity of RGD-containing adenoviral proteins conjugated to sulfonated aluminium phthalocyanines in integrin-expressing A549 lung and HeP2 laryngeal cancer cells. ${ }^{18}$

Carbohydrates have also been used to directly target endogenous lectins (carbohydrate binding proteins) with expression patterns that correlate with neoplastic transformation. The first report of carbohydrate targeting for PDT described the conjugation, characterisation and in vitro assessment of the photosensitiser chlorin e6 conjugated to a galactosyl polymer. ${ }^{19}$ More recently, mannose functionalised silica nanoparticles containing a porphyrin derivative photosensitiser have been used to target the specific lectin receptors overexpressed by HCT-116 human colorectal adenocarcinoma cells. ${ }^{20}$ Targeting with mannose moieties doubled the PDT cytotoxicity of the silica nanoparticles in vitro and allowed for effective HCT-116 tumour reduction following in vivo PDT of a subcutaneous mouse model. Conversely, exogenous lectins, such as wheat germ agglutinin ${ }^{21}$ and peanut agglutinin ${ }^{22}$ have also been used for the targeting of cell surface carbohydrates that exhibit expression patterns that are associated with malignancy.

The Thomsen-Friedenreich carbohydrate antigen (T antigen) is a truncated $O$-linked oncofoetal glycan that is exposed in more than $90 \%$ of primary tumours. ${ }^{23}$ The first report of using lectins for targeted photodynamic cancer therapy described the synthesis and PDT efficacy of a conjugate composed of the lectin, Morniga G, and a water soluble porphyrin photosensitiser. ${ }^{24}$ PDT using the Morniga G-porphyrin conjugate, targeted towards the T antigen, reduced Jurkat 
leukaemia cell viability by more than $90 \%$, whereas the non-conjugated sensitiser had no phototoxic effects at the same concentration. ${ }^{24}$ We have previously shown that jacalin, a lectin specific for the T antigen, can selectively deliver C11Pc-PEG gold nanoparticles to HT-29 human colon adenocarcinoma cells that overexpress the T antigen. Targeted PDT treatment lead to an exceptional reduction in viability whereas incubation in the dark and non-targeted PDT treatment was largely non-cytotoxic. ${ }^{25}$

In this present study, we compare, for the first time, the targeted PDT efficacy of C11Pc-PEG gold nanoparticles functionalised with either the lectin jacalin or with anti-HER-2 monoclonal antibodies. We demonstrate how targeting using lectins or antibodies can enhance PDT treatment response in both HT-29 colon cancer cells and in SK-BR-3 breast cancer cells, as compared to treatment with non-conjugated nanoparticles. We have shown that targeted PDT with jacalin or anti-HER-2 antibodies conjugated to our C11Pc-PEG nanoparticles induce similar levels of cytotoxicity. Our findings emphasise the importance of receptor density on cell surfaces in addition to the binding affinity of ligands for their respective targets when assessing potential targeting efficiency. With a high density of cancer-associated receptors on the cellular surface, the therapeutic value of weaker-binding targeting ligands may be significantly elevated. Finally, using confocal microscopy and lysosomal colocalisation studies, the internalisation mechanisms of the lectin or antibody nanoparticle conjugates in both cell lines have been analysed and found to be largely through the endocytic pathway.

\section{Materials and Methods}

\section{Synthesis of the C11Pc-PEG gold nanoparticles and conjugation of targeting ligands}

The synthesis and purification of the C11Pc-PEG gold nanoparticles was performed as previously reported..$^{25}$ Jacalin (Vector Laboratories) and monoclonal rat IgG2a anti-HER-2 antibodies (Abcam) were covalently conjugated to the PEG carboxyl groups on the C11Pc-PEG gold nanoparticles using $N$-(3-Dimethylaminopropyl)- $N$ '-ethylcarbodiimide (EDC; Sigma-Aldrich) and $N$-hydroxysuccinimide (NHS; Fisher Scientific). The carboxyl moieties on the PEG were converted to amine-reactive NHS esters by stirring the C11Pc-PEG gold nanoparticles $(2 \mathrm{ml}, 6 \mu \mathrm{M}$ C11Pc 
equivalent) for $30 \mathrm{~min}$ at room temperature in $50 \mathrm{mM} \mathrm{MES} \mathrm{buffer} \mathrm{(} \mathrm{pH} \mathrm{5.5,} \mathrm{0.05 \%} \mathrm{Tween} \mathrm{20)} \mathrm{with}$ $2 \mathrm{mM}$ EDC $(0.8 \mu \mathrm{l}, 0.877 \mathrm{~g} / \mathrm{ml})$ and $5 \mathrm{mM} \mathrm{NHS}(1.2 \mathrm{mg}, 115.08 \mathrm{~g} / \mathrm{mol})$. Unreacted EDC and NHS were removed by ultrafiltration of the NHS-ester functionalised C11Pc-PEG gold nanoparticles in four separate $500 \mu$ laliquots in Vivaspin ${ }^{\mathrm{TM}} 500$ tubes (100 kDa molecular weight cut off (MWCO), polyethersulfone (PES); Sartorius Stedim Biotech). The ultrafiltration procedure was performed by centrifuging the nanoparticle samples in the Vivaspin ${ }^{\mathrm{TM}} 500$ tubes at 14,300 xg for $30 \mathrm{~min}$ at $4^{\circ} \mathrm{C}$. The NHS-ester functionalised C11Pc-PEG gold nanoparticles in two of the Vivaspin ${ }^{\mathrm{TM}} 500$ tubes were each redispersed in 10 mM HEPES buffered saline $(500 \mu \mathrm{l} ; \mathrm{pH} 7.4,150 \mathrm{mM} \mathrm{NaCl}, 100$ $\mu \mathrm{M} \mathrm{CaCl} 2$ ). The nanoparticle samples in the two remaining Vivaspin ${ }^{\mathrm{TM}} 500$ tubes were each redispersed in $10 \mathrm{mM}$ phosphate buffered saline (PBS, $500 \mu \mathrm{l}$; pH 7.4, $150 \mathrm{mM} \mathrm{NaCl}, 100 \mu \mathrm{M}$ $\left.\mathrm{CaCl}_{2} \cdot 2 \mathrm{H}_{2} \mathrm{O}\right)$. Jacalin $\left(15.87 \mu \mathrm{l}, 1 \mathrm{mg} \cdot \mathrm{ml}^{-1}\right)$ was added to the NHS-ester functionalised C11Pc-PEG gold nanoparticles dispersed in the HEPES buffered saline $(1 \mathrm{ml})$ and anti-HER-2 antibodies (18.51 $\mu \mathrm{l}, 1 \mathrm{mg} \cdot \mathrm{ml}^{-1}$ ) were added to the nanoparticles dispersed in the PBS $(1 \mathrm{ml})$. The HEPES and PBS buffers are recommended by the suppliers of jacalin and the antibody, respectively. The final concentration of jacalin or anti-HER-2 antibodies mixed with the nanoparticles was $0.24 \mu \mathrm{M}$. The jacalin and the anti-HER-2 antibodies were stirred with the NHS-ester functionalised C11Pc-PEG gold nanoparticles overnight at room temperature. Unbound jacalin and anti-HER-2 antibodies were removed from the conjugated nanoparticles by six repeated ultrafiltrations of the nanoparticle samples in $500 \mu \mathrm{l}$ aliquots in Vivaspin ${ }^{\mathrm{TM}} 500$ tubes (100 kDa MWCO, PES) by centrifuging at $14,300 \times g$ at $4^{\circ} \mathrm{C}$ for $30 \mathrm{~min}$. After the sixth centrifugation the jacalin conjugated or anti-HER-2 antibody conjugated C11Pc-PEG nanoparticles prepared for use with the HT-29 cells were redispersed in serum-free Roswell Park Memorial Institute (RPMI) 1640 medium (Invitrogen) supplemented with $1.5 \mathrm{mM}$ L-glutamine (L-Gln; Invitrogen), as previously recommended in a study of jacalin and HT-29 cells. ${ }^{26}$ The jacalin or anti-HER-2 antibody conjugated C11Pc-PEG gold nanoparticles prepared for use with the SK-BR-3 cells were redispersed in serum-free Dulbecco's Modified Eagle Medium (DMEM; Invitrogen) supplemented with $1 \mathrm{mM}$ L-Gln, as previously described. ${ }^{11}$ As a control, non-conjugated C11Pc-PEG gold nanoparticles were also prepared in serum-free RPMI 1640 medium or serum-free DMEM medium, depending on the cell line used. All nanoparticle preparations were characterised using 
a Hitachi U-3010 UV-visible absorption spectrophotometer, appropriately diluted for in vitro experiments using either serum-free RPMI 1640 medium or serum-free DMEM medium, and stored at $4^{\circ} \mathrm{C}$.

Singlet oxygen measurement of the jacalin conjugated or anti-HER-2 antibody conjugated C11Pc-PEG gold nanoparticles

The production of singlet oxygen following the irradiation of jacalin conjugated or anti-HER-2 antibody conjugated C11Pc-PEG gold nanoparticles was measured using the molecular probe anthracene-9,10-dipropionic acid disodium salt (ADPA, 366.32 g.mol ${ }^{-1}$; Molecular Probes). ${ }^{27}$ The singlet oxygen production of both conjugates was compared to that of non-conjugated C11PcPEG. Non-conjugated, jacalin conjugated or anti-HER-2 antibody conjugated C11Pc-PEG gold nanoparticles were centrifuged in $500 \mu$ l aliquots in Vivaspin ${ }^{\mathrm{TM}} 500$ tubes at 14,300 xg for $30 \mathrm{~min}$ at $4^{\circ} \mathrm{C}$. The nanoparticle samples were each redispersed in $10 \mathrm{mM}$ PBS $(500 \mu \mathrm{l} ; \mathrm{pH} 7.4,150 \mathrm{mM}$ $\mathrm{NaCl}, 100 \mu \mathrm{M} \mathrm{CaCl} 2.2 \mathrm{H}_{2} \mathrm{O}$ ). The C11Pc-PEG gold nanoparticle preparations (450 $\mu \mathrm{l}$ ) were individually placed in a $1.5 \mathrm{ml}$ stoppered quartz cuvette with ADPA (50 $\mu \mathrm{l}, 1.7 \mathrm{mM}$ in methanol) and a magnetic stirrer bar. The samples were irradiated at $633 \mathrm{~nm}$ for 30 min using a $10 \mathrm{~mW}$ Helium-Neon (HeNe) Laser (JDS Uniphase) with continuous magnetic stirring. The absorbance of the ADPA was monitored at $400 \mathrm{~nm}$ every $5 \mathrm{~min}$.

\section{Culturing HT-29 human colon adenocarcinoma cells and SK-BR-3 human breast adenocarcinoma cells}

HT-29 human colon adenocarcinoma cells (LGC Standards) were cultured in NUNC Nunclon ${ }^{\text {TM }} \Delta$ T75 sterile culture flasks in RPMI 1640 medium supplemented with 1.5 mM L-Gln and 10\% Foetal Bovine Serum (FBS). SK-BR-3 human breast adenocarcinoma cells (LGC Standards) were cultured in T75 culture flasks using DMEM supplemented with $1 \mathrm{mM} \mathrm{L-GIn}$ and 10\% FBS. All cells were incubated in a humidified incubator at $37^{\circ} \mathrm{C}$ in a $5 \% \mathrm{CO}_{2}$ atmosphere and grown to $\mathrm{ca} .75 \%$ confluency prior to use. 


\section{Comparative targeted PDT of HT-29 cells - MTT viability assay}

HT-29 cells at a ca. 75\% confluency were trypsinised by washing once in PBS (5 $\mathrm{ml}$ ) then once in $0.25 \%$ Trypsin with EDTA ( $1 \mathrm{ml}$; Invitrogen). The $\mathrm{HT}-29$ cells were incubated at $37^{\circ} \mathrm{C}$ in a $5 \% \mathrm{CO}_{2}$ atmosphere for ca. 3 min until the cells detached from the culture flask. The detached cells were redispersed in RPMI 1640 medium supplemented with $1.5 \mathrm{mM} \mathrm{L-Gln}$ and 10\% FBS (10 ml) and counted using a Neubauer hemocytometer. The HT-29 cells were seeded onto two separate white opaque NUNC Nunclon ${ }^{\mathrm{TM}} \Delta$ Surface 96 well multidishes $\left(100 \mu \mathrm{l}, 2 \times 10^{4}\right.$ cells per well; Thermo Fisher Scientific) $24 \mathrm{~h}$ prior to incubation with the nanoparticles. The medium was then aspirated and the cells were washed once in PBS $(100 \mu l)$. The washed HT-29 cells were incubated with non-conjugated, jacalin conjugated or anti-HER-2 antibody conjugated C11Pc-PEG gold nanoparticles in serum-free RPMI 1640 medium (50 $\mu \mathrm{l} ; 0.00,0.10,0.20,0.50,1.00$ or $1.15 \mu \mathrm{M}$ equivalent of $\mathrm{C} 11 \mathrm{Pc}$ ) for $3 \mathrm{~h}$ at $37^{\circ} \mathrm{C}$ in a $5 \% \mathrm{CO}_{2}$ atmosphere. Following incubation, the cell medium containing nanoparticles was aspirated and the cells were washed 3 times in PBS (100 $\mu \mathrm{l})$. Finally the cells were kept in RPMI 1640 medium supplemented with $1.5 \mathrm{mM} \mathrm{L-GIn}$ and $10 \%$ FBS (200 $\mu$ l). Staurosporine ( $20 \mu \mathrm{M}$; LC Labs) was used as a positive control for cytotoxicity. ${ }^{28}$ One of the 96 well multidishes was kept in the dark as a control. The cells in the remaining 96 well multidish were irradiated for 6 min per well using a $10 \mathrm{~mW} 633 \mathrm{~nm}$ HeNe laser fitted with a biconvex diverging lens, giving a fluency rate of $29 \mathrm{~mW} . \mathrm{cm}^{-2}$ and a total light dose of $10.5 \mathrm{~J} . \mathrm{cm}^{-2}$. Light intensity was measured using a Power Max 500AD Molectron power meter. The laser was positioned $50 \mathrm{~cm}$ above the cells. Following irradiation, the cells were incubated at $37^{\circ} \mathrm{C}$ in a $5 \%$ $\mathrm{CO}_{2}$ atmosphere for $48 \mathrm{~h}$. MTT reagent (10 $\mu \mathrm{l}, 5 \mathrm{mg}^{-\mathrm{ml}^{-1}}$ in PBS) was added to each well and the cells were incubated at $37{ }^{\circ} \mathrm{C}$ in a $5 \% \mathrm{CO}_{2}$ atmosphere for $4 \mathrm{~h}$. The well contents were then removed and the formazan was dissolved in DMSO $(200 \mu \mathrm{l})$. The well contents were transferred to transparent 96 well multidishes and the absorbance was measured at $550 \mathrm{~nm}$ using a MRXDynatech plate reader. Background absorbance at $550 \mathrm{~nm}$ of RPMI 1640 medium alone incubated with MTT reagent was subtracted from all measurements. Cell viability was calculated as a percentage of absorbance at $550 \mathrm{~nm}$ of untreated, non-irradiated HT-29. All assays were performed in triplicate. 


\section{Comparative targeted PDT of SK-BR-3 cells - CellTiter-Blue ${ }^{\mathrm{TM}}$ viability assay}

SK-BR-3 cells at a ca. 75\% confluency were trypsinised and seeded into 96 well multidishes for 24 $\mathrm{h}$ as described for the HT-29 cells. The SK-BR-3 cells were washed once in PBS (100 $\mu$ l) prior to incubation with the nanoparticles. The washed SK-BR-3 cells were incubated with nonconjugated, jacalin conjugated or anti-HER-2 antibody conjugated C11Pc-PEG gold nanoparticles in serum-free DMEM medium ( $50 \mu \mathrm{l} ; 0.00,0.10,0.20,0.50,1.00$ or $1.15 \mu \mathrm{M}$ equivalent of C11Pc) for $3 \mathrm{~h}$ at $37^{\circ} \mathrm{C}$ in a $5 \% \mathrm{CO}_{2}$ atmosphere. Following incubation, the cell medium containing nanoparticles was aspirated and the cells were washed 3 times in PBS $(100 \mu l)$. Finally the cells were kept in DMEM medium supplemented with $1 \mathrm{mM} \mathrm{L-GIn}$ and 10\% FBS $(200 \mu \mathrm{l})$. Staurosporine $(20 \mu \mathrm{M})$ was used as a positive control for cytotoxicity. One of the 96 well multidishes was kept in the dark as a control. The cells in the remaining 96 well multidish were irradiated for 6 min per well using the $633 \mathrm{~nm}$ HeNe. Following irradiation, the cells were incubated for $48 \mathrm{~h}$ at $37^{\circ} \mathrm{C}$ in a $5 \% \mathrm{CO}_{2}$ atmosphere. CellTiter-Blue ${ }^{\mathrm{TM}}$ reagent (20 $\mu \mathrm{l}$ per well) was added to the cells and incubated for $4 \mathrm{~h}$ at $37{ }^{\circ} \mathrm{C}$ in a $5 \% \mathrm{CO}_{2}$ atmosphere. Fluorescence emission at $590 \mathrm{~nm}$ (excitation at $560 \mathrm{~nm}$ ) was measured using an EnVision ${ }^{\mathrm{TM}}$ (Wallac) 2103 Multilabel Reader (Perkin Elmer) equipped with an EnVision ${ }^{\mathrm{TM}}$ work station. Background fluorescence emission at $590 \mathrm{~nm}$ of DMEM medium alone incubated with CellTiter-Blue ${ }^{\mathrm{TM}}$ reagent was subtracted from all measurements. Cell viability was calculated as a percentage of fluorescence emission at $590 \mathrm{~nm}$ of untreated, non-irradiated SK-BR-3 cells. All assays were performed in triplicate.

\section{Colocalisation studies using laser scanning confocal microscopy}

The HT- 29 cells and the SK-BR-3 cells were seeded ( $2 \times 10^{4}$ cells per well) onto $18 \mathrm{~mm}$ round glass coverslips (Jencons VWR) in transparent 6 well multidishes (Thermo Fisher Scientific) for $48 \mathrm{~h}$ prior to nanoparticle incubation. The cells were then washed once in PBS (1 ml) and incubated for $3 \mathrm{~h}$ with serum-free RPMI 1640 medium (HT-29 cells) or serum-free DMEM medium (SK-BR-3 cells) containing jacalin or anti-HER-2 antibody conjugated C11Pc-PEG gold nanoparticles (1 $\mu \mathrm{M}$ C11Pc equivalent, $1 \mathrm{ml}$ ). Following incubation with the nanoparticles, the cells were washed 3 
times in PBS (1 ml) and finally kept in their respective media containing $10 \% \mathrm{FBS}(2 \mathrm{ml})$. The cells were incubated for $15 \mathrm{~h}$ at $37^{\circ} \mathrm{C}$ in a $5 \% \mathrm{CO}_{2}$ atmosphere. Prior to imaging, the cells were incubated for $1 \mathrm{~h}$ with LysoSensor ${ }^{\mathrm{TM}}$ Green DND-189 (1 $\mu \mathrm{M}$ from $1 \mathrm{mM}$ stock in DMSO; Invitrogen). The coverslips were mounted on a heated stage $\left(37^{\circ} \mathrm{C}\right)$ and $1 \mathrm{ml}$ imaging medium (120 mM NaCl, $5 \mathrm{mM} \mathrm{KCl}, 2 \mathrm{mM} \mathrm{CaCl} 2.2 \mathrm{H}_{2} \mathrm{O}, 1 \mathrm{mM} \mathrm{MgCl} 2.4 \mathrm{H}_{2} \mathrm{O}, 1 \mathrm{mM} \mathrm{NaH}_{2} \mathrm{PO}_{4}, 1 \mathrm{mM} \mathrm{NaHCO}_{3}$, $25 \mathrm{mM}$ HEPES, $11 \mathrm{mM}$ glucose, and $1 \mathrm{mg} \cdot \mathrm{ml}^{-1} \mathrm{BSA}$ ) was added to each coverslip. The cells were visualised with differential interference contrast (DIC) imaging using transmitted light from the $458 \mathrm{~nm}$ line of an Argon ion laser. The fluorescence of the C11Pc-PEG gold nanoparticles was visualised using excitation from a $633 \mathrm{~nm}$ HeNe laser and the red emission was collected using a $650 \mathrm{~nm}$ long pass filter. The fluorescence of the LysoSensor ${ }^{T M}$ Green DND-189 was visualised using excitation from the $458 \mathrm{~nm}$ line of the Argon ion laser and the green emission was collected using a 475-525 nm band pass filter. Colocalisation of the C11Pc-PEG gold nanoparticles with the LysoSensor $^{\mathrm{TM}}$ Green DND-189 was assessed by the yellow coloration of the merged red and green fluorescence images overlaid with the DIC images.

\section{Results}

\section{Preparation of photoactive lectin and antibody nanoparticle conjugates}

Zinc phthalocyanine-polyethylene glycol (C11Pc-PEG) functionalised gold nanoparticles (ca. 4 $\mathrm{nm}$ ) were synthesised as previously reported. ${ }^{25}$ The synthetic procedure involved the reduction of gold chloride by sodium borohydride in the presence of both $\alpha$-thio- $\omega$-carboxy PEG and a thiolated 11-alkyl zinc phthalocyanine (C11Pc). The water soluble C11Pc-PEG gold nanoparticles (6 $4 \mathrm{M}$ C11Pc equivalent) were covalently bound to jacalin or rat monoclonal anti-HER-2 IgG2a antibodies using EDC/NHS coupling. Based on the approximation that ca. 155 molecules of C11Pc were bound to each nanoparticle, a $6 \mu \mathrm{M}$ solution of C11Pc-PEG gold nanoparticles contained $c a$. 38.7 nM gold nanoparticles. ${ }^{25}$ By reacting a ca. $38.7 \mathrm{nM}$ solution of EDC/NHS-activated C11PcPEG gold nanoparticles with $240 \mathrm{nM}$ jacalin or anti-HER-2 antibodies the targeting ligands were at a 6.2-fold molar excess of gold nanoparticles. Therefore, it is thought that approximately 6 targeting ligands were present on each nanoparticle. Further, it was estimated that $65 \%$ of the 
PEG molecules on each nanoparticle remain unconjugated. Figure 1 shows schematic representations of jacalin conjugated (A) and anti-HER-2 antibody conjugated (B) C11Pc-PEG gold nanoparticles.
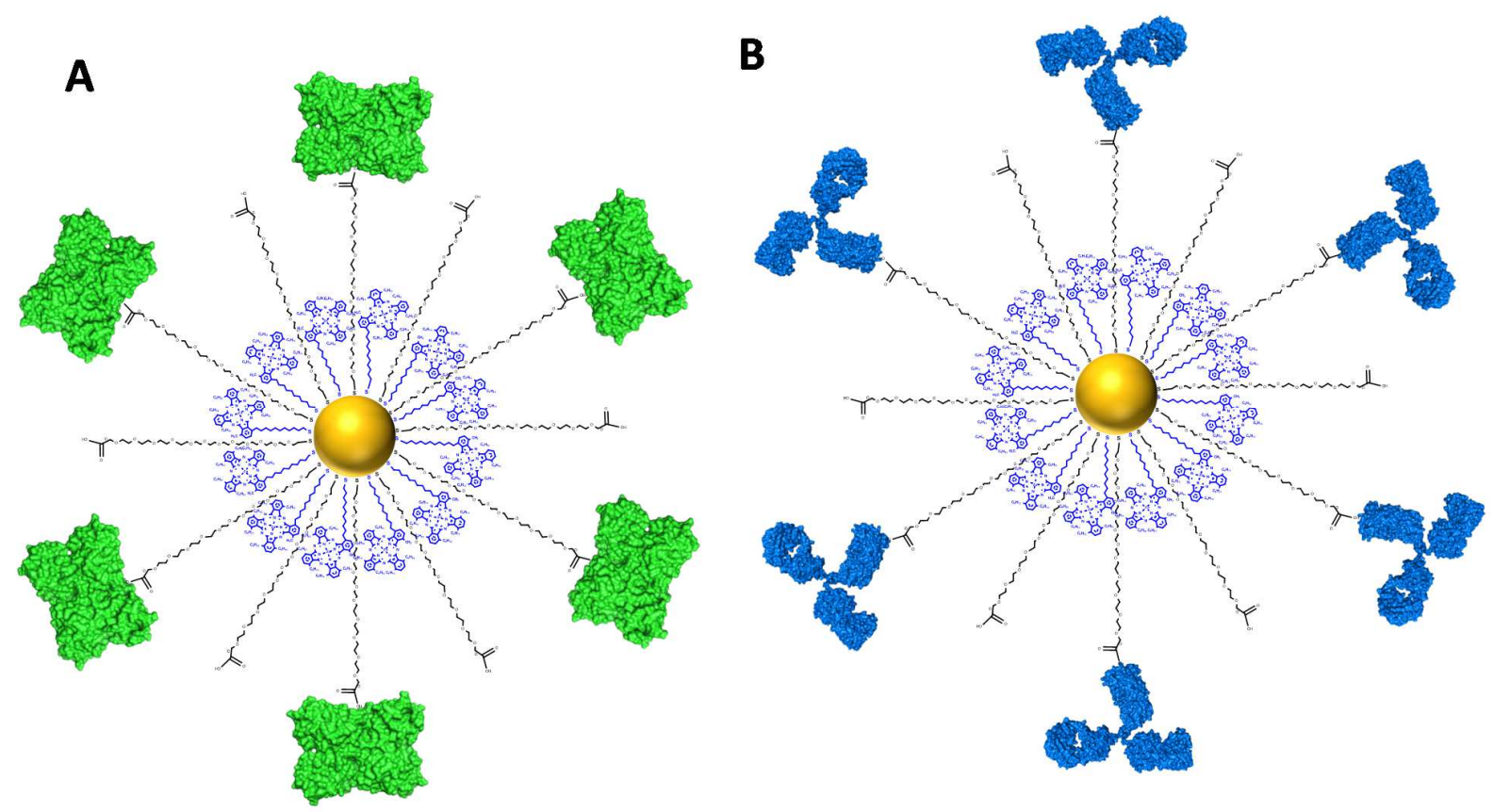

Figure 1 Schematic representations of C11Pc-PEG gold nanoparticles covalently bound to A) jacalin or B) anti-HER-2 antibodies. The gold nanoparticles are depicted as the core spherical clusters, the PEG molecules are shown as black linear polymer molecules, and the C11Pc photosensitiser is shown as blue, surface-bound macrocyclic structures. Images of jacalin (PDB ID 1M26) ${ }^{29}$ and the IgG2a antibody (PDB ID 1IGT) ${ }^{30}$ were generated using PyMOL.

To compare the PDT efficiency of the jacalin conjugates with that of the anti-HER-2 antibody conjugates, the singlet oxygen production following the irradiation of the conjugated C11Pc-PEG gold nanoparticles was investigated. Non-conjugated C11Pc-PEG gold nanoparticles were used as a control. The production of singlet oxygen was measured in PBS using anthracene-9,10dipropionic acid disodium salt (ADPA) as the colorimetric singlet oxygen probe. ${ }^{27}$ ADPA exhibits characteristic absorption bands from 300-400 nm, which photobleach when the molecule reacts with singlet oxygen to produce an endoperoxide. The quantification of singlet oxygen was 
calculated using a 1:1 molar stoichiometry of singlet oxygen to ADPA. The number of moles of singlet oxygen produced were normalised to the concentration of C11Pc equivalent present in the nanoparticle samples. Figure $\mathbf{2}$ shows that there is no significant difference in the quantity of singlet oxygen produced following the irradiation of the C11Pc-PEG gold nanoparticles conjugated to either jacalin (Figure 2, green) or the anti-HER-2 antibody (Figure 2, blue). Following conjugation to either targeting proteins, the singlet oxygen production of the nanoparticle conjugates appears to be marginally less than that produced by the non-conjugated C11Pc-PEG gold nanoparticles (Figure 2, black). However, the slight reduction in photoactivity following conjugation of the nanoparticles to either of the targeting ligands should be compensated by significantly enhanced cellular internalisation of the conjugates. Previously, we have shown that irradiation at $633 \mathrm{~nm}$ of 'control' (C11Pc-free) PEG gold nanoparticles (ca. $4 \mathrm{~nm}$ in diameter) in the presence of ADPA did not result in any photobleaching of ADPA, confirming that the C11Pc is essential for the production of singlet oxygen. ${ }^{11}$

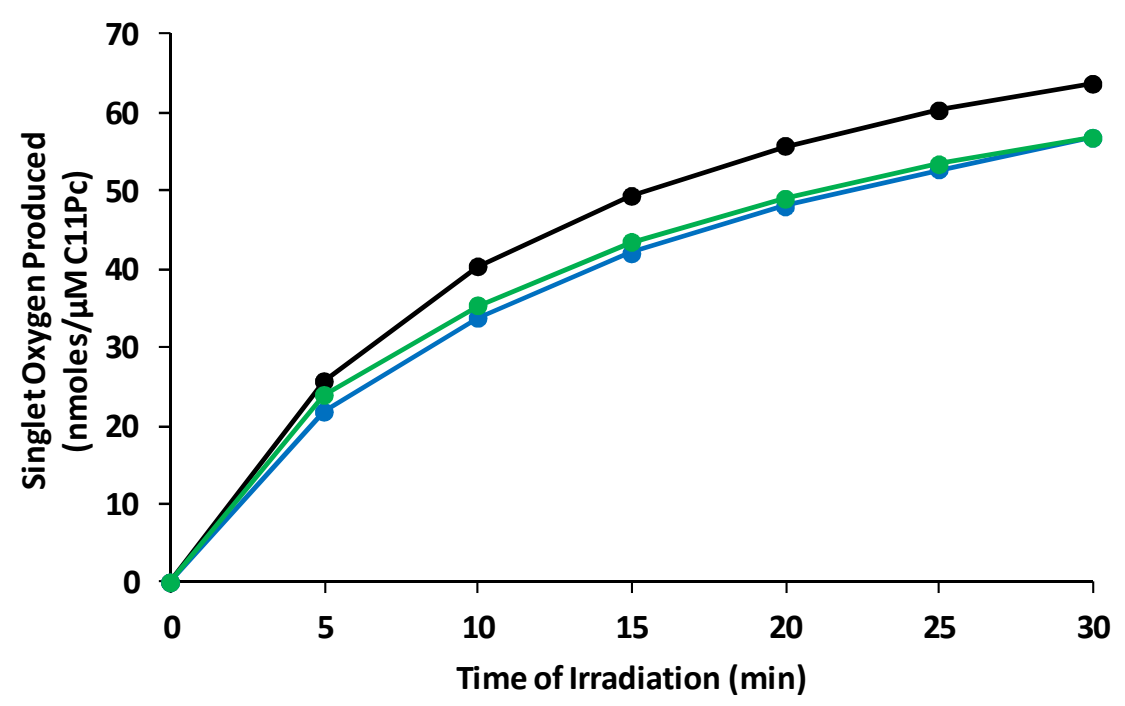

Figure 2 Singlet oxygen production following the irradiation at $633 \mathrm{~nm}$ of non-conjugated (black), jacalin conjugated (green) and anti-HER-2 antibody conjugated (blue) C11Pc-PEG gold nanoparticles. All nanoparticle samples were irradiated in $10 \mathrm{mM}$ PBS ( $\left.\mathrm{pH} 7.4,150 \mathrm{mM} \mathrm{NaCl}, 100 \mu \mathrm{M} \mathrm{CaCl}_{2} .2 \mathrm{H}_{2} \mathrm{O}\right)$ in the presence of the colorimetric singlet oxygen molecular probe ADPA. 


\section{Targeted PDT efficacy of the conjugated nanoparticles}

We have reported previously the absorption, excitation and emission spectra of C11Pc assembled on gold nanoparticles. ${ }^{31,32}$ The absorption maximum of the phthalocyanine on the gold nanoparticles is $c a .690 \mathrm{~nm}$. In this present study, with consideration of the convenience of using a Helium Neon laser, we excited the C11Pc-PEG gold nanoparticle conjugates within the cells at $633 \mathrm{~nm}$. This wavelength is within the phthalocyanine absorption band envelope, and has been shown previously to be a suitable wavelength for the irradiation of anti-HER2 antibody or jacalin conjugated C11Pc-PEG nanoparticles within cancer cell lines. ${ }^{11,25}$ Additionally, to ensure that the lectin ligand targets the specific cell surface receptor, we have previously demonstrated that the targeted phototoxicity of the jacalin conjugated nanoparticles was competitively inhibited by the presence of the free sugar methyl- $\alpha$-galactopyrannoside or the T antigen-expressing glycoprotein asialofetuin. ${ }^{25}$ Similarly, the selectivity of anti-HER-2 antibody was highlighted by showing that the antibody conjugated nanoparticles were not phototoxic to breast cancer cell lines (MDA-MB231 and MCF-10A) that do not over-express the HER-2 receptor. ${ }^{11}$

HT-29 human colon adenocarcinoma cells were incubated with non-conjugated, jacalin conjugated or anti-HER-2 antibody conjugated C11Pc-PEG gold nanoparticles (0.00-1.15 $\mu \mathrm{M}$ C11Pc equivalent) and irradiated at $633 \mathrm{~nm}$ at a final light dose of $10.5 \mathrm{~J} . \mathrm{cm}^{-2}$. Treatment response of the HT-29 cells was assessed using a MTT viability assay $48 \mathrm{~h}$ following PDT. The viability of the cells following jacalin targeted or anti-HER-2 antibody targeted PDT is shown in Figure $\mathbf{3}$ (A and B respectively). Following irradiation, viability of the HT-29 cells incubated with $1.15 \mu \mathrm{M}$ C11Pc equivalent of the jacalin conjugated or anti-HER-2-conjugated nanoparticles was reduced to $c a$. $10.1 \%$ and $c a .19 .2 \%$, respectively. Statistical significance was calculated using a one-tailed student's $t$-test, which confirmed a statistically significant reduction in viability following irradiation $(P<0.05)$. Without irradiation, at the same nanoparticle concentration, viability remained at $c a .62 .0 \%$ and $c a$. $77.3 \%$, respectively. No significant difference in the dosedependent phototoxicity of the HT-29 cells was observed following targeted PDT treatment using jacalin conjugated (Figure 3C, green) or anti-HER-2 antibody conjugated (Figure 3C, blue) nanoparticles at concentrations of 0.0-0.5 $\mu \mathrm{M}$ C11Pc equivalent. 
At $1.15 \mu \mathrm{M}$ C11Pc equivalent, phototoxicity induced by the jacalin conjugated nanoparticles was ca. $9.3 \%$ greater than that induced by the anti-HER-2 antibody conjugated particles $(P<0.05)$. However, at the nanoparticle concentration of $1.15 \mu \mathrm{M}$ C11Pc equivalent the jacalin conjugated particles exhibited a greater level of dark toxicity, ca. $38 \%$ reduction in viability, as compared to the dark toxicity of the antibody conjugates, $c a .23 \%$ reduction in viability. Partial reductions in the metabolic activities of cells incubated with the jacalin conjugated nanoparticles were observed without irradiation. Reduction in cellular metabolic activity is a common non-toxic biological response induced by jacalin binding that is dependent on lectin concentration, cell type and could be influenced by passage number. ${ }^{26}$ In HT-29 cells, jacalin has been found to interfere with the pro-survival mitogen-activated protein kinase (MAPK) signalling pathway. ${ }^{33}$ Analogous to HER-2 downregulation that is observed during HER-2 targeted therapies, the anti-proliferative biological effects of jacalin could be exploited to provoke a combined synergistic anti-tumour effect, further amplifying the effectiveness of jacalin targeted PDT. Irradiation of HT-29 cells incubated with 0.00-1.15 $\mu \mathrm{M}$ C11Pc equivalent of non-conjugated nanoparticles did not result in any significant phototoxicity, as the viability of HT-29 cells incubated with the highest nanoparticle concentration remained at $94 \%$ following irradiation (Figure 3C, black). At nanoparticle concentrations of 0.20-1.15 $\mu \mathrm{M}$ C11Pc equivalent, targeted PDT treatment using either jacalin or anti-HER-2 antibody conjugates potentiated significant phototoxicity of the HT29 cells, as compared to non-targeted treatment $(P<0.05)$. Such enhancement emphasises the critical significance of using cancer-cell selective endocytic ligands such as lectins and antibodies to minimise non-specific photodamage. 

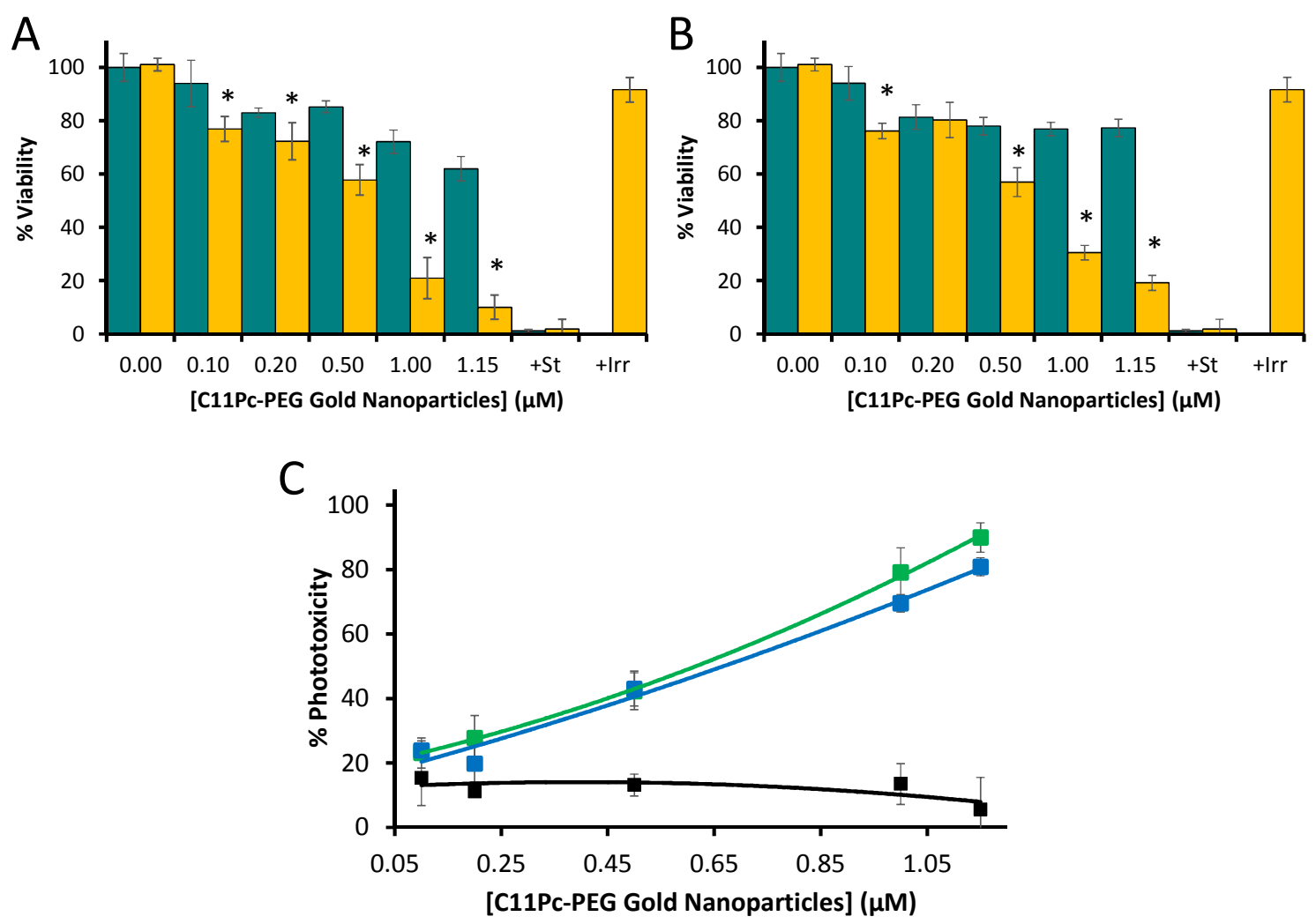

Figure 3 MTT viability assay results of HT-29 cells following PDT treatment with: $(A)$ the jacalin conjugated; or (B) anti-HER-2 antibody conjugated C11Pc-PEG gold nanoparticles. Cells were irradiated at $633 \mathrm{~nm}$ for 6 min per well (orange) or nonirradiated (dark cyan). C) Phototoxicity of HT-29 cells incubated with the jacalin conjugated (green line), anti-HER-2 antibody conjugated (blue line) or nonconjugated (black line) nanoparticles. Staurosporine $(+\mathrm{St}, 20 \mu \mathrm{M})$ was used as a positive control for cytotoxicity. Cells irradiated but not incubated with nanoparticles (+Irr) were also used as a control. (Error bars are $\pm 95 \%$ confidence intervals, $\mathrm{n}=3 . *$ indicates statistical significance in viability reduction following irradiation at $P<0.05$ using a one-tailed $t$-test.)

Targeted PDT using jacalin or anti-HER-2 antibody nanoparticle conjugates was also investigated with the SK-BR-3 human breast adenocarcinoma cells. A MTT assay was attempted with the SKBR-3 cells following targeted PDT treatment. However, residual DMEM medium in the wells during the formazan solubilisation step caused significant variation in the formazan colour (data not shown). ${ }^{34}$ Therefore, the CellTiter-Blue ${ }^{\mathrm{TM}}$ fluorimetric cell viability assay was performed with 
the SK-BR-3 cells following targeted PDT treatment since no solubilisation step is involved with this assay.

Figure 4 clearly demonstrates that following targeted PDT, with the same range of nanoparticle concentrations, the viability of the SK-BR-3 cells appears to be significantly lower than that of the HT-29 cells. The lower viability of the SK-BR-3 cells could be due to the SK-BR-3 cells being more susceptible to phototoxicity by having less effective repair mechanisms, that facilitate recovery from oxidative damage, than the HT-29 cells. ${ }^{35}$

At nanoparticle concentrations of $1 \mu \mathrm{M}$ and $1.15 \mu \mathrm{M}$ C11Pc equivalent, targeted PDT using either the jacalin (Figure 4A) or anti-HER-2 antibody (Figure 4B) conjugates dramatically reduced SKBR-3 cell viability with $>99 \%$ cell kill. Viability, without irradiation, remained at $c a .58 .9-70.2 \%$ (Figure 4A) and ca. 85.5-98.5\% (Figure 4B), respectively. The limited dark toxicity observed with the anti-HER-2 antibody conjugates offers an obvious advantage over using the jacalin nanoparticle conjugates. As observed with the HT-29 cells, the phototoxicity of the SK-BR-3 cells induced by non-conjugated C11Pc-PEG gold nanoparticles was negligible at all nanoparticle concentrations used for these experiments (Figure 4C). A dose-dependence in phototoxicity of the SK-BR-3 cells incubated with the jacalin or anti-HER-2 antibody conjugated particles was also observed. Jacalin conjugation appeared to provide a statistically significant improved PDT effect at $0.10 \mu \mathrm{M}$ C11Pc equivalent, as compared to anti-HER-2 antibody conjugation $(P<0.05)$. However, this apparent improvement in PDT efficacy when targeting SK-BR-3 cells using the jacalin conjugates ( $0.10 \mu \mathrm{M}$ C11Pc equivalent) was accompanied by a ca. $4 \%$ greater dark toxicity than when the cells were incubated with the anti-HER-2 antibody conjugates. 

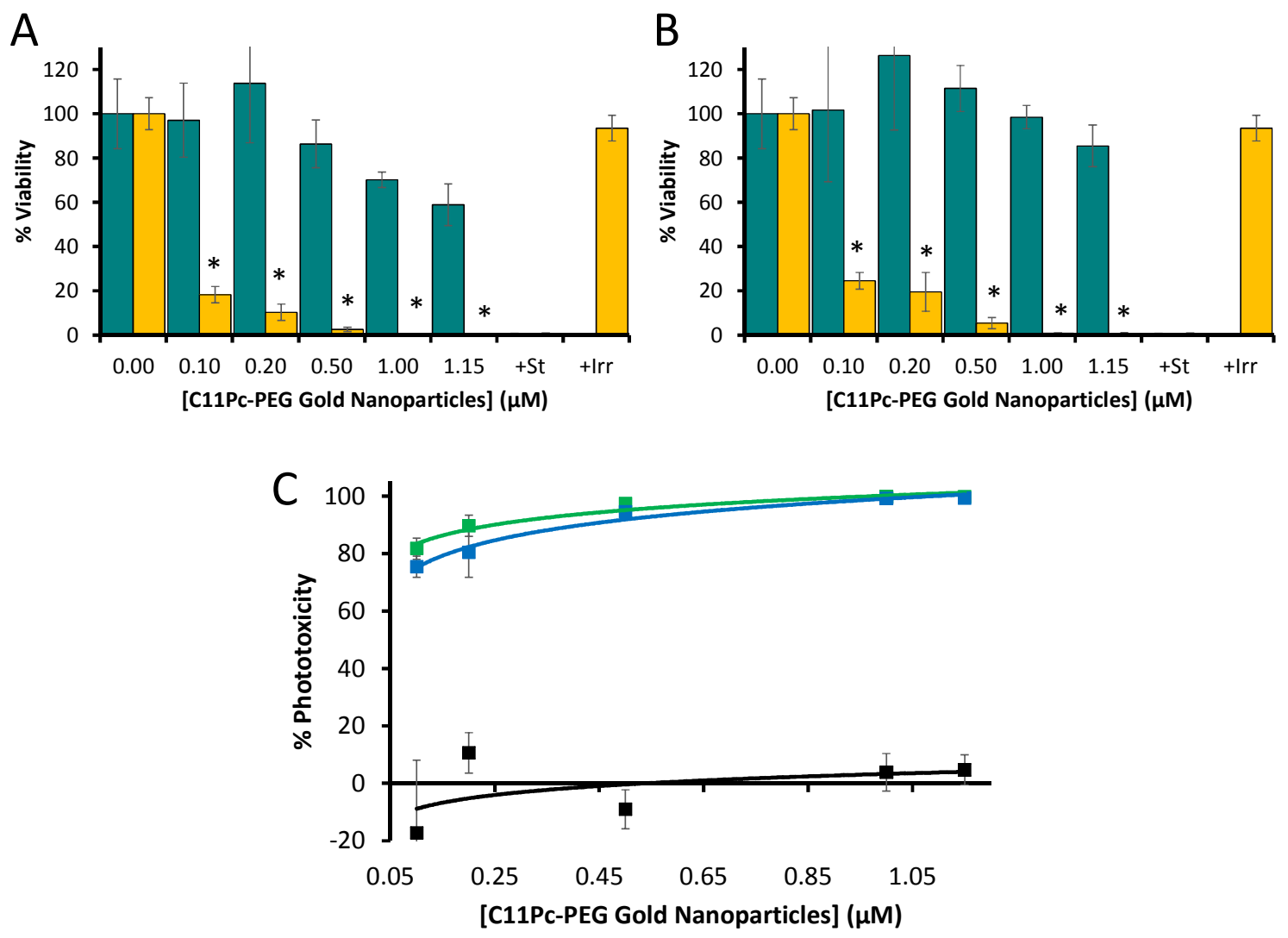

Figure 4 CellTiter-Blue ${ }^{T M}$ viability assay results of SK-BR-3 cells following PDT treatment with: (A) jacalin conjugated; or (B) anti-HER-2 antibody conjugated C11Pc-PEG gold nanoparticles. Cells were irradiated at $633 \mathrm{~nm}$ for 6 min per well (orange) or non-irradiated (dark cyan). C) Phototoxicity of SK-BR-3 cells incubated with the jacalin conjugated (green line), anti-HER-2 antibody conjugated (blue line) and non-conjugated (black line) nanoparticles. Staurosporine $(+S t, 20 \mu \mathrm{M})$ was used as a positive control for cytotoxicity. Cells irradiated but not incubated with nanoparticles (+Irr) were also used as a control. (Error bars are $\pm 95 \%$ confidence intervals, $\mathrm{n}=3 . *$ indicates statistical significance in viability reduction following irradiation at $P<0.05$ using a one-tailed $t$-test.)

The HER-2 receptor is overexpressed in SK-BR-3 human breast adenocarcinoma cells and in HT29 human colorectal adenocarcinoma cells. ${ }^{36,37}$ SK-BR-3 cells are reported to express ca. $1-2 \times 10^{6}$ HER-2 receptors per cell, ${ }^{38}$ and IgG anti-HER-2 monoclonal antibodies are known to bind to these cells with a $\mathrm{K}_{d}$ of $14-36 \mathrm{nM} .{ }^{39} \mathrm{HT}-29$ cells are reported to express ca. $4.4 \pm 0.3 \times 10^{7} \mathrm{~T}$ antigens per cell, while jacalin binds to the $T$ antigen with a $K_{d}$ of $500 \mathrm{nM} .{ }^{26}$ The cell viability results shown in 
Figure 3 and Figure 4 suggest that the lower binding affinity of jacalin ( $K_{d}$ of $\left.500 n M\right)$ is compensated by the higher expression levels of the $\mathrm{T}$ antigen $\left(4.4 \times 10^{7}\right.$ antigens per cell) when compared to the higher binding affinity of the anti-HER-2 antibody ( $K_{d}$ of 14-36 nM) for targeting the lower density HER-2 receptor ( $2 \times 10^{6}$ receptors per cell). The higher level of expression of the T antigen in combination with the tetravalency of jacalin exemplifies the potential of lectins as multivalent targeting agents that can selectively deliver therapeutic nanoparticles to cancer cells. Either as an alternative to antibodies or in combination with antibodies, lectin targeting has a distinct role in cancer therapeutics by providing selectivity for an independent class of biological targets in addition to intrinsic anti-tumour biological activities that are non-overlapping with those exhibited by antibodies.

Once the PDT efficacy of the jacalin conjugated and the anti-HER-2 antibody conjugated C11PcPEG gold nanoparticles with both HT-29 cells and SK-BR-3 cells had been established, the intracellular fate of both nanoparticle conjugates was examined using laser scanning confocal microscopy. HT-29 cells and SK-BR-3 cells were incubated with jacalin or anti-HER-2 antibody conjugated C11Pc-PEG gold nanoparticles (1 1 M C11Pc equivalent). The cells were also incubated with LysoSensor ${ }^{\mathrm{TM}}$ Green DND-189, a marker of acidic organelles. It has been shown previously that nanoparticles, such as functionalised gold nanoparticles, can be internalised into cells through a receptor mediated endocytic pathway which results in intracellular accumulation within the endosomal compartments. ${ }^{40,41}$ Maturation of endosomes leads to their eventual acidification through combination with lysosomes via the endocytic degradation pathway. ${ }^{42}$ Alternatively, internalised nanoparticles in the endosomes may be redirected to the extracellular domain prior to endosomal maturation and acidification. ${ }^{43}$ Colocalisation of nanoparticle conjugates with acidic organelle markers would suggest that the conjugates are uptaken through an endocytic pathway rather than passive diffusion by which many lipophilic photosensitisers can enter cells. ${ }^{42,} 44$

Acidic organelles within the HT-29 cells and SK-BR-3 cells were visualised using the green fluorescent marker LysoSensor ${ }^{\mathrm{TM}}$ Green DND-189 (1 $\left.\mu \mathrm{M}\right)$ using excitation at $458 \mathrm{~nm}$. The fluorescence of C11Pc upon excitation at $633 \mathrm{~nm}$ was exploited to visualise the conjugated C11Pc-PEG gold nanoparticles ( $1 \mu \mathrm{M}$ C11Pc equivalent) within the intracellular environment. 
Colocalisation of the nanoparticle conjugates with LysoSensor ${ }^{\mathrm{TM}}$ Green DND-189 was assessed using the BiolmageXD software which correlates the red and green channels present in one voxel (volumetric pixel). Regions of colocalised red and green fluorescence from the conjugated C11PcPEG gold nanoparticles and the acidic organelles, respectively, were isolated and false coloured yellow. Figure 5 shows the laser scanning confocal microscope images of SK-BR-3 cells incubated with the jacalin conjugated C11Pc-PEG gold nanoparticles (Figure 5A, red) and LysoSensor ${ }^{\mathrm{TM}}$ Green DND-189 (Figure 5B, green). For the image shown in Figure 5B the brightness of the green channel was reduced by $9 \%$ for clarity; however, colocalisation isolation and analysis using the BiolmageXD software was performed on unaltered images. Figure 5C (yellow) highlights the regions of colocalisation where the jacalin conjugated nanoparticles are in the vicinity of the LysoSensor $^{\mathrm{TM}}$ Green DND-189 indicating their presence within the acidified endosomal compartments. The DIC image of the SK-BR-3 cells merged with the fluorescence images of the jacalin conjugated C11Pc-PEG gold nanoparticles and the LysoSensor ${ }^{T M}$ Green DND-189 is shown in Figure 5D. Similar patterns of colocalisation were observed in the SK-BR-3 cells incubated with anti-HER-2 antibody conjugated C11Pc-PEG gold nanoparticles (Figure S1 in Supporting Information) and in the HT-29 cells incubated with the jacalin conjugated (Figure S2) or anti-HER2 antibody conjugated (Figure S3) C11Pc-PEG gold nanoparticles. The colocalisation analysis suggests that both nanoparticle conjugates are internalised within the endolysosomes in both HT-29 cells and SK-BR-3 cells. Intracellular localisation of photosensitising agents has a considerable effect on the mechanisms of cell death, as the lysosomal presence of a photosensitiser can promote sub-apoptotic and necrotic mechanisms of cell death. ${ }^{45}$ These findings agree with our previous results which suggest that jacalin targeted PDT induced cell death of HT-29 cells via necrosis. ${ }^{25}$ The perinuculear presence of the jacalin conjugated or antiHER-2 antibody conjugated nanoparticles in HT-29 cells and SK-BR-3 cells suggests that targeted PDT using such nanoparticle conjugates is potentially advantageous since there is a lower risk of genotoxicity. ${ }^{46}$ 


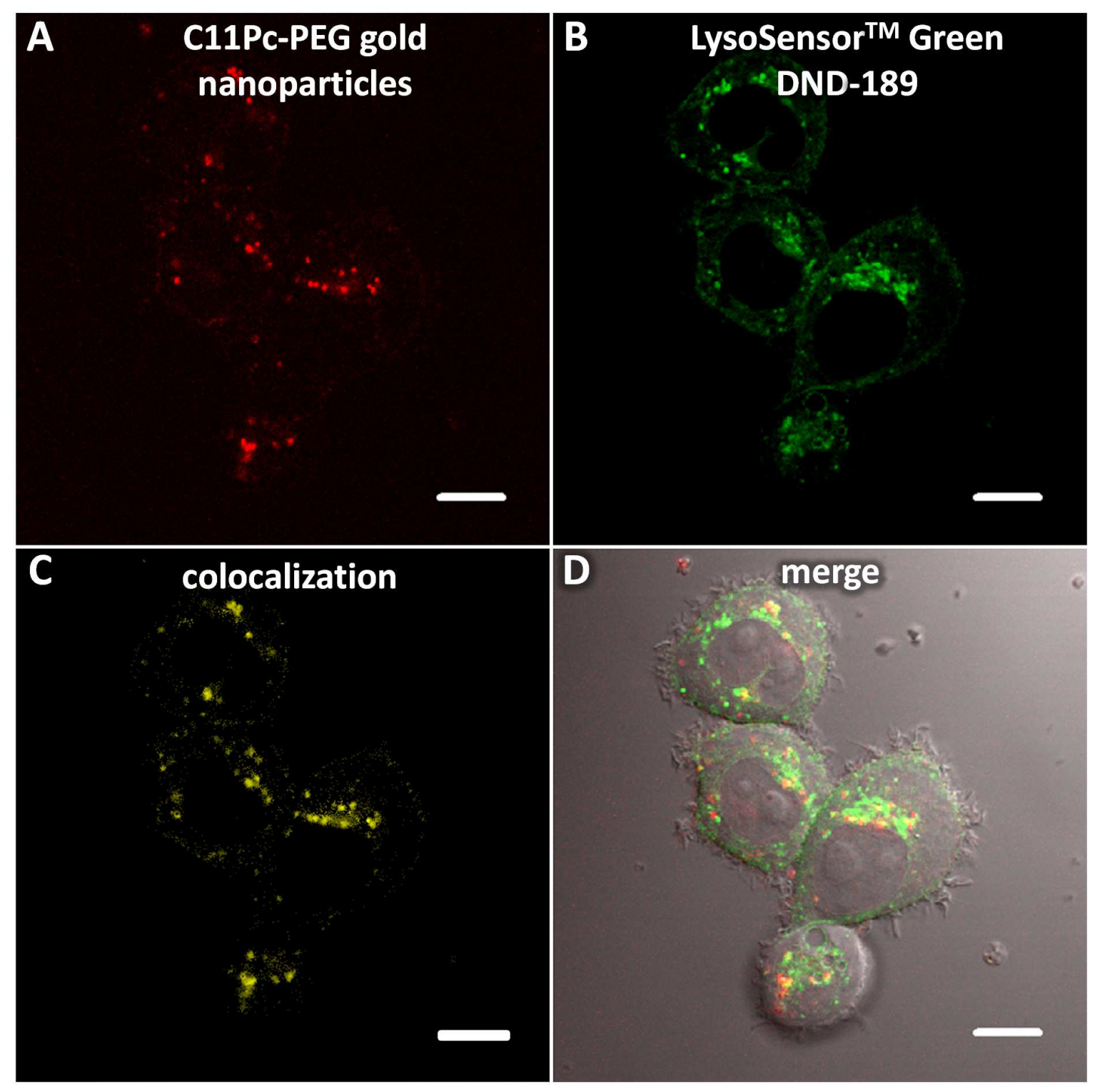

Figure 5 Confocal microscopy images of SK-BR-3 cells incubated with the jacalin conjugated C11Pc-PEG gold nanoparticles ( $1 \mu \mathrm{M}$ C11Pc equivalent). A) Excitation of the conjugated C11Pc-PEG gold nanoparticles at $633 \mathrm{~nm}$ results in red fluorescence emission. B) Acidic organelles are visualised by the green fluorescence emission of LysoSensor ${ }^{\mathrm{TM}}$ Green DND-189 upon excitation at $458 \mathrm{~nm}$. C) Colocalisation of the conjugated C11Pc-PEG gold nanoparticles and the LysoSensor ${ }^{T M}$ Green DND-189 is shown in yellow. D) The DIC image and the fluorescence images of C11Pc and the LysoSensor ${ }^{\mathrm{TM}}$ Green DND-189 were merged. (Scale bars are $10 \mu \mathrm{m}$ ). 


\section{Conclusions}

Cancer cell targeting using the lectin jacalin as a carbohydrate-specific targeting protein was compared to anti-HER-2 antibodies which target the overexpressed HER-2 receptor. Both targeting ligands were covalently conjugated to C11Pc-PEG gold nanoparticles and were found to produce similar quantities of singlet oxygen upon irradiation at $633 \mathrm{~nm}$. The MTT viability assay showed that the nanoparticles conjugated to either jacalin or anti-HER-2 antibodies drastically reduced HT-29 colon cancer cell viability, as compared to the non-conjugated particles. At a nanoparticle concentration of $1.15 \mu \mathrm{M}$ C11Pc equivalent, HT-29 cell viability was reduced to $c a$. $10 \%$ and $19 \%$ following jacalin or anti-HER-2 antibody targeted PDT treatment, respectively. However, at the same concentration, viability of the HT-29 cells incubated with non-conjugated particles remained at ca. 94\%. The targeted PDT efficiency of jacalin and anti-HER-2 antibody conjugated C11Pc-PEG gold nanoparticles was also compared with SK-BR-3 breast cancer cells and analysed using the CellTiter-Blue viability assay. The SK-BR-3 cells appeared to be significantly more susceptible to PDT damage than the HT-29 cells following treatment using the same concentration of nanoparticles. At a nanoparticle concentration of $1.15 \mu \mathrm{M} \mathrm{C11Pc}$ equivalent, SK-BR-3 cell viability was reduced to $c a$. $3 \%$ and $5 \%$ following targeted PDT treatment with nanoparticles conjugated to jacalin or anti-HER-2 antibodies, respectively. However, at the same concentration, non-conjugated nanoparticles reduced SK-BR-3 cell viability by only $c a$. $5 \%$ following irradiation. A clear advantage of anti-HER-2 antibody targeting is the lower levels of dark toxicity observed following incubation with either the HT-29 cells or the SK-BR-3 cells, as compared to dark incubation with the jacalin conjugates.

The intracellular localisation of the jacalin conjugated and anti-HER-2 antibody conjugated C11Pc-PEG gold nanoparticles was investigated in both HT-29 cells and SK-BR-3 cells using laser scanning confocal microscopy. Accumulation of the targeted nanoparticle conjugates within acidic organelles was assessed by the colocalisation of the red $\mathrm{C11Pc}$ fluorescence from the conjugated nanoparticles with the green fluorescence of the LysoSensor ${ }^{\mathrm{TM}}$ Green DND-189 lysosomal marker. The degree of colocalisation was analysed using BiolmageXD software. It was found that both the jacalin conjugated and anti-HER-2 antibody conjugated nanoparticles 
partially colocalised with the LysoSensor ${ }^{\mathrm{TM}}$ Green DND-189 and remained in the acidic organelles within both the HT-29 cells and the SK-BR-3 cells. Colocalisation suggests that both types of nanoparticle conjugates were internalised through receptor mediated endocytosis. Further investigations into nanoparticle internalisation and recycling of HER-2 receptors and T antigenbearing glycoproteins could provide a valuable insight into the differences of cellular uptake of the targeted nanoparticle conjugates. Based on the dissociation constants of jacalin binding to HT-29 cells $(500 \pm 50 \mathrm{nM})^{26}$ and anti-HER-2 antibodies binding to SK-BR-3 cells (14-36 nM), ${ }^{39}$ it was expected that targeting with the antibody would be significantly more effective than the lectin. However, it is reported that there are a significantly greater number of T antigens on HT-

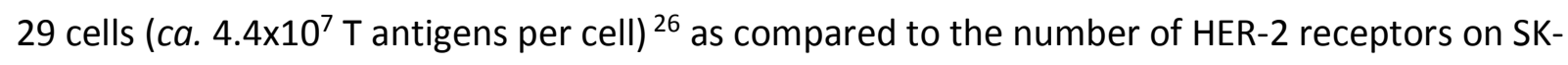
BR-3 cells (ca. $1-2 \times 10^{6}$ HER-2 receptors per cell). ${ }^{38}$ Since the PDT efficacy of the C11Pc PEG gold nanoparticle conjugated to either the jacalin lectin or anti-HER-2 antibody was comparable for either cell line, our results suggest a critical role for cell surface receptor density on the outcome of targeted PDT treatments for cancer. Investigations into the binding kinetics of the nanoparticle conjugates to the cells could help highlight the subtle differences between using the lectin or the antibody. The results described outline how lectins, such as jacalin, may have great potential for targeted cancer therapy by exploiting the high levels of cancer-associated carbohydrate antigen expression. Additionally, the dual targeting of two cancer-associated receptors that are biochemically different in nature may expand the applications of selective PDT through combining both targeting ligands onto one bi-specific nanoparticle.

\section{Acknowledgements}

The authors are grateful to the EPSRC for a post-graduate studentship for G.O. and to Dr. Paul Thomas for assistance with the confocal microscopy. 


\section{References}

1. T. J. Dougherty, C. J. Gomer, B. W. Henderson, G. Jori, D. Kessel, M. Korbelik, J. Moan and Q. Peng, Photodynamic therapy, J. Natl. Cancer Inst., 1998, 90, 889-905.

2. D. Bechet, P. Couleaud, C. Frochot, M. L. Viriot, F. Guillemin and M. Barberi-Heyob, Nanoparticles as vehicles for delivery of photodynamic therapy agents, Trends Biotechnol., 2008, 26, 612-621.

3. M. E. Davis, Z. G. Chen and D. M. Shin, Nanoparticle therapeutics: an emerging treatment modality for cancer, Nat. Rev. Drug Discov., 2008, 7, 771-782.

4. D. Schrama, R. A. Reisfeld and J. C. Becker, Antibody targeted drugs as cancer therapeutics, Nat. Rev. Drug Discov., 2006, 5, 147-159.

5. A. J. Bullous, C. M. Alonso and R. W. Boyle, Photosensitiser-antibody conjugates for photodynamic therapy, Photochem. Photobiol. Sci., 2011, 10, 721-750.

6. D. Mew, C. K. Wat, G. H. Towers and J. G. Levy, Photoimmunotherapy: treatment of animal tumors with tumor-specific monoclonal antibody-hematoporphyrin conjugates, J. Immunol., 1983, 130, 1473-1477.

7. B. Q. Spring, A. O. Abu-Yousif, A. Palanisami, I. Rizvi, X. Zheng, Z. Mai, S. Anbil, R. B. Sears, L. B. Mensah, R. Goldschmidt, S. S. Erdem, E. Oliva and T. Hasan, Selective treatment and monitoring of disseminated cancer micrometastases in vivo using dual-function, activatable immunoconjugates, Proc. Natl. Acad. Sci. U. S. A., 2014, 111, E933-942.

8. Y. Yarden and M. X. Sliwkowski, Untangling the ErbB signalling network, Nature reviews. Molecular cell biology, 2001, 2, 127-137.

9. J. S. Ross and J. A. Fletcher, The HER-2/neu oncogene in breast cancer: prognostic factor, predictive factor, and target for therapy, Stem Cells, 1998, 16, 413-428.

10. D. J. Slamon, B. Leyland-Jones, S. Shak, H. Fuchs, V. Paton, A. Bajamonde, T. Fleming, W. Eiermann, J. Wolter, M. Pegram, J. Baselga and L. Norton, Use of chemotherapy plus a monoclonal antibody against HER2 for metastatic breast cancer that overexpresses HER2, $N$. Engl. J. Med., 2001, 344, 783-792.

11. T. Stuchinskaya, M. Moreno, M. J. Cook, D. R. Edwards and D. A. Russell, Targeted photodynamic therapy of breast cancer cells using antibody-phthalocyanine-gold nanoparticle conjugates, Photochem. Photobiol. Sci., 2011, 10, 822-831.

12. J. Sudimack and R. J. Lee, Targeted drug delivery via the folate receptor, Adv. Drug Delivery Rev., 2000, 41, 147-162.

13. M. M. Qualls and D. H. Thompson, Chloroaluminum phthalocyanine tetrasulfonate delivered via acid-labile diplasmenylcholine-folate liposomes: intracellular localization and synergistic phototoxicity, International journal of cancer. Journal international du cancer, 2001, 93, 384392.

14. C. S. Jin, L. Cui, F. Wang, J. Chen and G. Zheng, Targeting-triggered porphysome nanostructure disruption for activatable photodynamic therapy, Adv. Healthc. Mater., 2014, 3, 1240-1249.

15. D. Hogemann-Savellano, E. Bos, C. Blondet, F. Sato, T. Abe, L. Josephson, R. Weissleder, J. Gaudet, D. Sgroi, P. J. Peters and J. P. Basilion, The transferrin receptor: A potential molecular imaging marker for human cancer, Neoplasia, 2003, 5, 495-506.

16. M. R. Hamblin and E. L. Newman, Photosensitizer targeting in photodynamic therapy. I. Conjugates of haematoporphyrin with albumin and transferrin, J. Photochem. Photobiol., $B$, 1994, 26, 45-56.

17. W. Arap, R. Pasqualini and E. Ruoslahti, Cancer treatment by targeted drug delivery to tumor vasculature in a mouse model, Science, 1998, 279, 377-380. 
18. C. M. Allen, W. M. Sharman, C. La Madeleine, J. M. Weber, R. Langlois, R. Ouellet and J. E. van Lier, Photodynamic therapy: tumor targeting with adenoviral proteins, Photochem. Photobiol., 1999, 70, 512-523.

19. J. Kopeček, B. Ǩíhová and N. Krinick, Targetable photoactivatable polymeric drugs, J. Controlled Release, 1991, 16, 137-143.

20. M. Gary-Bobo, Y. Mir, C. Rouxel, D. Brevet, I. Basile, M. Maynadier, O. Vaillant, O. Mongin, M. Blanchard-Desce, A. Morère, M. Garcia, J. O. Durand and L. Raehm, Mannose-functionalized mesoporous silica nanoparticles for efficient two-photon photodynamic therapy of solid tumors, Angew. Chem., Int. Ed., 2011, 50, 11425-11429.

21. A. Weissenbock, M. Wirth and F. Gabor, WGA-grafted PLGA-nanospheres: preparation and association with Caco-2 single cells, J. Controlled Release, 2004, 99, 383-392.

22. G. Konska, C. Vissac, K. Zagla, F. Chezet, M. P. Vasson, D. Bernard-Gallon and J. Guillot, Ultrastructural localization of binding sites for PNA and VVA-B(4) lectins in human breast cancer cell lines detected by confocal fluorescence microscopy, Int. J. Oncol., 2002, 21, 1009-1014.

23. G. F. Springer, T and Tn, general carcinoma autoantigens, Science, 1984, 224, 1198-1206.

24. G. Poiroux, M. Pitié, R. Culerrier, B. Ségui, E. J. Van Damme, W. J. Peumans, J. Bernadou, T. Levade, P. Rougé, A. Barre and H. Benoist, Morniga G: a plant lectin as an endocytic ligand for photosensitizer molecule targeting toward tumor-associated T/Tn antigens, Photochem. Photobiol., 2011, 87, 370-377.

25. G. Obaid, I. Chambrier, M. J. Cook and D. A. Russell, Targeting the oncofetal ThomsenFriedenreich disaccharide using jacalin-PEG phthalocyanine gold nanoparticles for photodynamic cancer therapy, Angew. Chem., Int. Ed., 2012, 51, 6158-6162.

26. L.-G. Yu, J. D. Milton, D. G. Fernig and J. M. Rhodes, Opposite effects on human colon cancer cell proliferation of two dietary Thomsen-Friedenreich antigen-binding lectins, J. Cell. Physiol., 2001, 186, 282-287.

27. B. A. Lindig, M. A. J. Rodgers and A. P. Schaap, Determination of the lifetime of singlet oxygen in D2O using 9,10-anthracenedipropionic acid, a water-soluble probe, J. Am. Chem. Soc., 1980, 102, 5590-5593.

28. R. Bertrand, E. Solary, P. O'Connor, K. W. Kohn and Y. Pommier, Induction of a Common Pathway of Apoptosis by Staurosporine, Exp. Cell Res., 1994, 211, 314-321.

29. A. A. Jeyaprakash, P. G. Rani, G. B. Reddy, S. Banumathi, C. Betzel, K. Sekar, A. Surolia and M. Vijayan, Crystal structure of the jacalin - T-antigen complex and a comparative study of lectin - Tantigen complexes, J. Mol. Biol., 2002, 321, 637-645.

30. L. J. Harris, S. B. Larson, K. W. Hasel and A. McPherson, Refined structure of an intact IgG2a monoclonal antibody, Biochemistry, 1997, 36, 1581-1597.

31. D. C. Hone, P. I. Walker, R. Evans-Gowing, S. FitzGerald, A. Beeby, I. Chambrier, M. J. Cook and D. A. Russell, Generation of cytotoxic singlet oxygen via phthalocyanine-stabilized gold nanoparticles: A potential delivery vehicle for photodynamic therapy, Langmuir, 2002, 18, 29852987.

32. M. E. Wieder, D. C. Hone, M. J. Cook, M. M. Handsley, J. Gavrilovic, D. A. Russell, Intracellular photodynamic therapy with photosensitizer-nanoparticle conjugates: Cancer therapy using a 'Trojan horse', Photochem. Photobiol. Sci., 2006, 5, 727-734.

33. L.-G. Yu, L. C. Packman, M. Weldon, J. Hamlett and J. M. Rhodes, Protein phosphatase 2A, a negative regulator of the ERK signaling pathway, is activated by tyrosine phosphorylation of putative HLA class II-associated protein I (PHAPI)/pp32 in response to the antiproliferative lectin, jacalin, J. Biol. Chem., 2004, 279, 41377-41383. 
34. H. Wang, F. Wang, X. Tao and H. Cheng, Ammonia-containing dimethyl sulfoxide: an improved solvent for the dissolution of formazan crystals in the 3-(4,5-dimethylthiazol-2-yl)-2,5-diphenyl tetrazolium bromide (MTT) assay, Anal. Biochem., 2012, 421, 324-326.

35. F. Q. Schafer and G. R. Buettner, Singlet oxygen toxicity is cell line-dependent: a study of lipid peroxidation in nine leukemia cell lines, Photochem. Photobiol., 1999, 70, 858-867.

36. W. K. Kim, M. H. Bang, E. S. Kim, N. E. Kang, K. C. Jung, H. J. Cho and J. H. Park, Quercetin decreases the expression of ErbB2 and ErbB3 proteins in HT-29 human colon cancer cells, $J$. Nutr. Biochem., 2005, 16, 155-162.

37. H. Xu, Y. Yu, D. Marciniak, A. K. Rishi, F. H. Sarkar, O. Kucuk and A. P. Majumdar, Epidermal growth factor receptor (EGFR)-related protein inhibits multiple members of the EGFR family in colon and breast cancer cells, Mol. Cancer Ther., 2005, 4, 435-442.

38. A. Orlova, M. Magnusson, T. L. Eriksson, M. Nilsson, B. Larsson, I. Hoiden-Guthenberg, C. Widstrom, J. Carlsson, V. Tolmachev, S. Stahl and F. Y. Nilsson, Tumor imaging using a picomolar affinity HER2 binding affibody molecule, Cancer Res., 2006, 66, 4339-4348.

39. Y. Tang, J. Wang, D. A. Scollard, H. Mondal, C. Holloway, H. J. Kahn and R. M. Reilly, Imaging of HER2/neu-positive BT-474 human breast cancer xenografts in athymic mice using (111)Intrastuzumab (Herceptin) Fab fragments, Nucl. Med. Biol., 2005, 32, 51-58.

40. M. J. Marín, F. Galindo, P. Thomas and D. A. Russell, Localized intracellular pH measurement using a ratiometric photoinduced electron-transfer-based nanosensor, Angew. Chem., Int. Ed., 2012, 51, 9657-9661.

41. R. Vacha, F. J. Martinez-Veracoechea and D. Frenkel, Intracellular release of endocytosed nanoparticles upon a change of ligand-receptor interaction, ACS Nano, 2012, 6, 10598-10605.

42. T. G. Iversen, T. Skotland and K. Sandvig, Endocytosis and intracellular transport of nanoparticles: Present knowledge and need for future studies, Nano Today, 2011, 6, 176-185.

43. S. Zhang, J. Li, G. Lykotrafitis, G. Bao and S. Suresh, Size-Dependent Endocytosis of Nanoparticles, Adv. Mater., 2009, 21, 419-424.

44. C. A. Robertson, D. H. Evans and H. Abrahamse, Photodynamic therapy (PDT): a short review on cellular mechanisms and cancer research applications for PDT, J. Photochem. Photobiol., B, 2009, 96, 1-8.

45. P. Boya and G. Kroemer, Lysosomal membrane permeabilization in cell death, Oncogene, 2008, 27, 6434-6451.

46. N. L. Oleinick and H. H. Evans, The photobiology of photodynamic therapy: cellular targets and mechanisms, Radiat. Res., 1998, 150, S146-156. 